\title{
Subthreshold Diode Micropulse Laser (SDM) for Persistent Macular Thickening and Limited Visual Acuity After Epiretinal Membrane Peeling
}

This article was published in the following Dove Press journal: Clinical Ophthalmology

\section{Jeffrey K Luttrull $\mathbb{D}$}

Private Practice, Ventura County Retina Vitreous Medical Group, Ventura, CA 93003, USA
Correspondence: Jeffrey K Luttrull 3160 Telegraph Road, Suite 230, Ventura, California 93003, USA

Tel/Fax + I 805-650-0865

Email jkluttrull@gmail.com
Purpose: To examine the effect of low-intensity/high-density subthreshold diode micropulse laser (SDM) on visual acuity (VA) and macular thickness in eyes with limited visual recovery and persistent macular thickening after epiretinal membrane peeling.

Methods: A retrospective review of medical records identified all patients undergoing SDM after membrane peeling in a clinical vitreoretinal subspecialty practice. Exclusion criteria included other obfuscating ocular disease or loss to follow-up after SDM treatment.

Results: All 19 eyes of 18 patients identified were included for study. After membrane peeling, VA improved from an avg. Snellen 20/240 [ $\log$ MAR 1.08] to 20/72 [0.56] $(\mathrm{p}=0.0004)$. Attributed to persistent macular thickening following membrane peeling, overall VAs then gradually declined to an avg. of 20/91 [0.66] by 4-109 months (avg. 41) post vitrectomy, at which point panmacular SDM was performed. An avg. 15 months post SDM, both VA (to avg. 20/68 [0.53]) and maximum macular thickness improved ( $\mathrm{p}=0.007$ and $\mathrm{p}=0.008$, respectively). There were no adverse treatment effects.

Conclusion: Low-intensity/high-density subthreshold (sublethal) diode micropulse laser (SDM) may reduce macular thickening and improve visual in eyes with persistent macular thickening after membrane peeling even years after vitrectomy.

Keywords: laser, micropulse, subthreshold, epiretinal membrane, macular thickening, macular edema, reset, heat-shock proteins

\section{Introduction}

Visual loss due to epiretinal membrane (ERM) is one of the most common indications for vitreoretinal surgery. The visual results of vitrectomy with membrane peeling (MP) are generally good. Most visual acuity improvements occur in the first few months after surgery but can continue for a year or more. ${ }^{1,2}$

The most important determinant of postoperative visual acuity (VA) is preoperative VA. The better the preoperative VA, the better the postoperative VA. ${ }^{1-3}$ Despite improvement, however, VA may remain limited after membrane peeling. Once surgical recovery has run its course, no reliable method of eliciting further visual improvement post membrane peeling has been described. ${ }^{1-3}$

ERMs often cause thickening of the underlying macula. While this generally improves after surgery, ERM-induced macular thickening may persist and limit visual recovery. Unlike inflammatory or retinovascular cystoid macular edema, the primarily tractionally induced macular thickening associated with ERMs, both before and after membrane peeling, often demonstrates little or no angiographic leakage and may be 
refractory to conventional medical treatment for macular edema, such as local and topical anti-inflammatory therapy. ${ }^{1-5}$

Low-intensity/high-density subthreshold (sublethal) diode micropulse laser (SDM) has been shown to be clinically effective for all conventional retinal laser applications (other than cautery) without adverse treatment effects; improve retinal and visual function in dry age-related macular degeneration (AMD), inherited retinal degenerations (IRD), and open-angle glaucoma (OAG); and reduce the incidence of neovascular conversion in high-risk dry AMD. ${ }^{6-25}$ The current study examines the effect of panmacular SDM on persistent macular thickening and limited visual recovery following vitrectomy for ERM.

\section{Methods}

This study adhered to the tenets of the Declaration of Helsinki and was approved by the Western Investigational Review Board. The records of all patients undergoing SDM in a retinal subspecialty practice were reviewed. Inclusion criteria were eyes having undergone pars plana vitrectomy with membrane peeling for visually significant ERMs and subsequently treated by panmacular SDM. With regard to the technique of membrane peeling, no vital dyes were employed and there was no intent to separately peel internal limiting membrane. Exclusionary criteria included other obfuscating ocular disease; other underlying causes of macular edema such as diabetes mellitus, retinal vascular occlusion, or uveitis; visually significant cataract or posterior capsule opacity; cataract surgery or posterior capsulotomy after SDM treatment; and loss to follow-up after SDM. No eye received medical therapy other than topical medications in the immediate post-vitrectomy recovery period. All retinal images, including Spectral-domain optical coherence tomography, were obtained with a Heidelberg Spectralis ${ }^{\mathrm{TM}}$ system (Heidelberg Engineering, Heidelberg, Germany).

Clinical data were recorded at the following times: (1) Last date prior to membrane peeling; (2) date of maximum visual improvement post membrane peeling; (3) date of panmacular SDM treatment; (4) date of final examination. For the purpose of statistical analysis, Snellen visual acuities were converted to $\operatorname{logMAR}$. SD-OCT parameters recorded were the Central Foveal Thickness (measured, in microns, at the foveal center) and Maximum Macular Thickness (measured, in microns, at the point of maximum retinal thickness within $2 \mathrm{~mm}$ of the foveal center).

\section{SDM Treatment}

The patients reported in this study were offered SDM in the absence of other generally effective treatments; and the demonstrated facility of SDM to improve macular function and visual acuity in a number of disparate clinical settings including diabetic macular edema, macular edema due to retinal vein occlusions, central serous chorioretinopathy, age-related macular degeneration, inherited retinopathies, and open-angle glaucoma; all in the absence of adverse treatment effects. ${ }^{6-25}$

Following informed consent and pupillary dilation, a topical anesthetic was applied to the cornea, followed by application of a Mainster Macular corneal contact lens (magnification factor $1.05 \times$, Ocular Instruments, Mentor, Ohio). Under biomicroscopic visualization, 800-1200 high-density/low-intensity subthreshold $810 \mathrm{~nm}$ diode laser applications, $200-\mu \mathrm{m}$ spot size, 1.45-watt power, $5 \%$ duty cycle, and 0.15 -second duration, were placed in confluent fashion throughout the posterior retina encompassed by the major vascular arcades (panmacular treatment). Thus, SDM treatment was uniform and identical in all eyes in all respects. ${ }^{6}$

Table I Eye-Level Characteristics, N (\%) or Mean (SD)

\begin{tabular}{|c|c|}
\hline Total Number of Patients & 18 \\
\hline Sex & \\
\hline Male & $9(50.0)$ \\
\hline Female & $9(50.0)$ \\
\hline Race & \\
\hline Caucasian & $13(72.2)$ \\
\hline Hispanic & $2(11.1)$ \\
\hline Asian & $2(11.1)$ \\
\hline Missing & I (5.6) \\
\hline Total Number of Eyes & 19 \\
\hline Eye & \\
\hline OD & $10(52.6)$ \\
\hline OS & $9(47.4)$ \\
\hline Pre-SDM VA, LogMAR & $0.6(0.3)$ \\
\hline Pre-SDM CMT & $364.6(155.7)$ \\
\hline Pre-SDM MMT & $482.3(88.4)$ \\
\hline Pre-PPV VA, LogMAR $\left(\mathrm{N}_{\text {miss }}=\mathrm{I}\right)$ & $0.7(0.3)$ \\
\hline Post-SDM VA, LogMAR & $0.4(0.3)$ \\
\hline Post-SDM CFT & $342.5(112.7)$ \\
\hline Post-SDM MMT & $448.3(74.0)$ \\
\hline Post-PPV VA, LogMAR $\left(\mathrm{N}_{\text {miss }}=1\right)$ & $0.4(0.3)$ \\
\hline
\end{tabular}

Abbreviations: $N$, number; $S D$, standard deviation; VA, visual acuity converted from Snellen; PPV, pars plana vitrectomy; CFT, central foveal thickness; MMT, maximum macular thickness; OD, right eye; OS, left eye. 
Table 2 Summary of Calculated Difference (Post-Treatment Minus Pre-Treatment)

\begin{tabular}{|l|l|l|}
\hline Variable & Mean (SD) & Median (IQR) \\
\hline Pre/Post SDM VA, LogMAR & $-0.18(0.26)$ & $-0.15(-0.30,0.00)$ \\
Pre/Post SDM CFT & $-22.05(76.39)$ & $2(-80,12)$ \\
Pre/Post SDM MMT & $-34.00(50.01)$ & $-14(-53,-6)$ \\
Pre-Post PPV VA, LogMAR & $-0.29(0.28)$ & $-0.30(-0.40,0.00)$ \\
\hline
\end{tabular}

Notes: Each row shows the difference (post-treatment minus pre-treatment) in pre/post SDM visual acuity, CFT, MMT, and pre/post PPV visual acuity. In order to test whether the mean difference is different from zero, paired t-tests were performed. A significant $p$-value indicates that the mean difference is significantly different from zero. Both visual acuity measures are significantly different pre-treatment versus post-treatment, with visual acuity measures decreasing (improving) after both PPV and SDM. Also, MMT is significantly different pre-treatment versus post-treatment. Since there are 19 eyes in the dataset from 18 patients, methods accounting for inter-eye correlation were not employed. As a sensitivity analysis, t-tests with 18 eyes from the 18 patients were performed, but the results did not change appreciably.

Abbreviations: OD, right eye; OS, left eye; SDM, high-density/low-intensity subthreshold diode micropulse laser; VA, visual acuity; CFT, central foveal thickness by spectral domain optical coherence tomography in microns; MMT, maximum macular thickness by spectral domain optical coherence tomography in microns; PPV, pars plana vitrectomy.

\section{Statistical Analysis}

The mean and median differences for the covariates of interest were determined and the difference (post-treatment minus pretreatment) in pre/post SDM visual acuity, CFT, MMT, and pre/ post PPV visual acuity calculated (Table 1). In order to test whether the mean difference was different from zero, paired $\mathrm{t}$-tests were performed. A significant $\mathrm{p}$-value indicated that the mean difference is significantly different from zero. Since there are 19 eyes in the dataset from 18 patients, methods accounting for inter-eye correlation were not employed. As a sensitivity analysis, t-tests with 18 eyes from the 18 patients were also performed (Table 2). The coefficients and p-values from six univariate linear models, predicting the difference (post-treatment minus pre-treatment) using pre-treatment values as the covariate, were also analyzed (Table 3 ).

\section{Results}

All patients identified as having undergone SDM following membrane peeling were eligible and included for study. This included 19 eyes of 18 patients, 9 male and 9

Table 3 Univariate Linear Models, Predicting Difference (PostTeatment Minus Pre-Treatment) with Pre-Treatment Value as Covariate

\begin{tabular}{|l|l|l|}
\hline Covariate & Coefficient (SD) & p-value \\
\hline Pre/Post SDM VA, LogMAR & $-0.25(0.23)$ & 0.30 \\
Pre/Post SDM CFT & $-0.36(0.08)$ & 0.0004 \\
Pre/Post SDM MMT & $-0.31(0.1)$ & 0.02 \\
Pre-Post PPV VA, LogMAR & $-0.41(0.19)$ & 0.048 \\
\hline
\end{tabular}

Notes: A significant association exists in the last three models, and in the negative direction. This indicates that as the pre-treatment value increases, the difference decreases, on average. A sensitivity analysis considering 18 eyes was performed to assess possible inter-eye correlation, and the results were not significantly different. Abbreviations: OD, right eye; OS, left eye; SDM, high-density/low-intensity subthreshold diode micropulse laser; VA, visual acuity; CFT, central foveal thickness by spectral domain optical coherence tomography in microns; MMT, maximum macular thickness by spectral domain optical coherence tomography in microns; PPV, pars plana vitrectomy. female, aged 58-92 years (avg. 75). All eyes were pseudophakic at the time of SDM treatment. None had visually significant posterior capsule opacities requiring posterior capsulotomy after SDM treatment.

Vitrectomy with membrane peeling for ERM had improved Snellen VAs from an avg. Snellen VA of 20/ 240 [ $\log$ MAR 1.08 ] prior to surgery, to an avg. of $20 / 72$ [0.56] $(\mathrm{p}=0.0004)$. (Table 1)

SDM was performed 4-109 months after membrane peeling (avg. 41 months). VAs at the time of SDM ranged 20/30 [0.18] - 20/200 [1.0]; avg. 20/91 [0.66].

Post-SDM follow-up ranged 1-42 months (avg. 15.2 months). After SDM, VA was significantly improved (range 20/20 [0] - 20/200 [1.00], avg. 20/68 [0.53]; $\mathrm{p}=0.007)$ (Table 1, Figures 1 and 2).

Central foveal thickness (CFT) by OCT at the time of SDM ranged 112 - 655 $\mu \mathrm{m}$ (avg. 365). After SDM, CFTs were unchanged (range 142-566 $\mu \mathrm{m}$, avg. 343) $(\mathrm{p}=0.22)$ (Table 1, Figures 3 and 4). Prior to SDM, one eye with a recurrent ERM prior to SDM had developed a lamellar macular hole and subnormal CFT of $112 \mu \mathrm{m}$. This lamellar defect resolved with restoration of a normal foveal umbo following SDM.

Maximum macular thickness (MMT) by OCT at the time of SDM ranged $323-701 \mu \mathrm{m}$ (avg. 482). After SDM, MMT improved (range 318-601, avg. 448) $(\mathrm{p}=0.008)$ (Table 1, Figures 5-10).

Linear regression analysis revealed significant negative correlations for CFT $(p=0.0004)$ and MMT $(p=0.02)$ after SDM. This association was not significant for logMAR VA $(\mathrm{p}=0.30)$ (Table 2$)$.

\section{Discussion}

Vitrectomy with membrane peeling is a highly effective intervention for visual loss due to epiretinal membranes. ${ }^{1,2}$ 


\section{Pre/Post SDM VA}

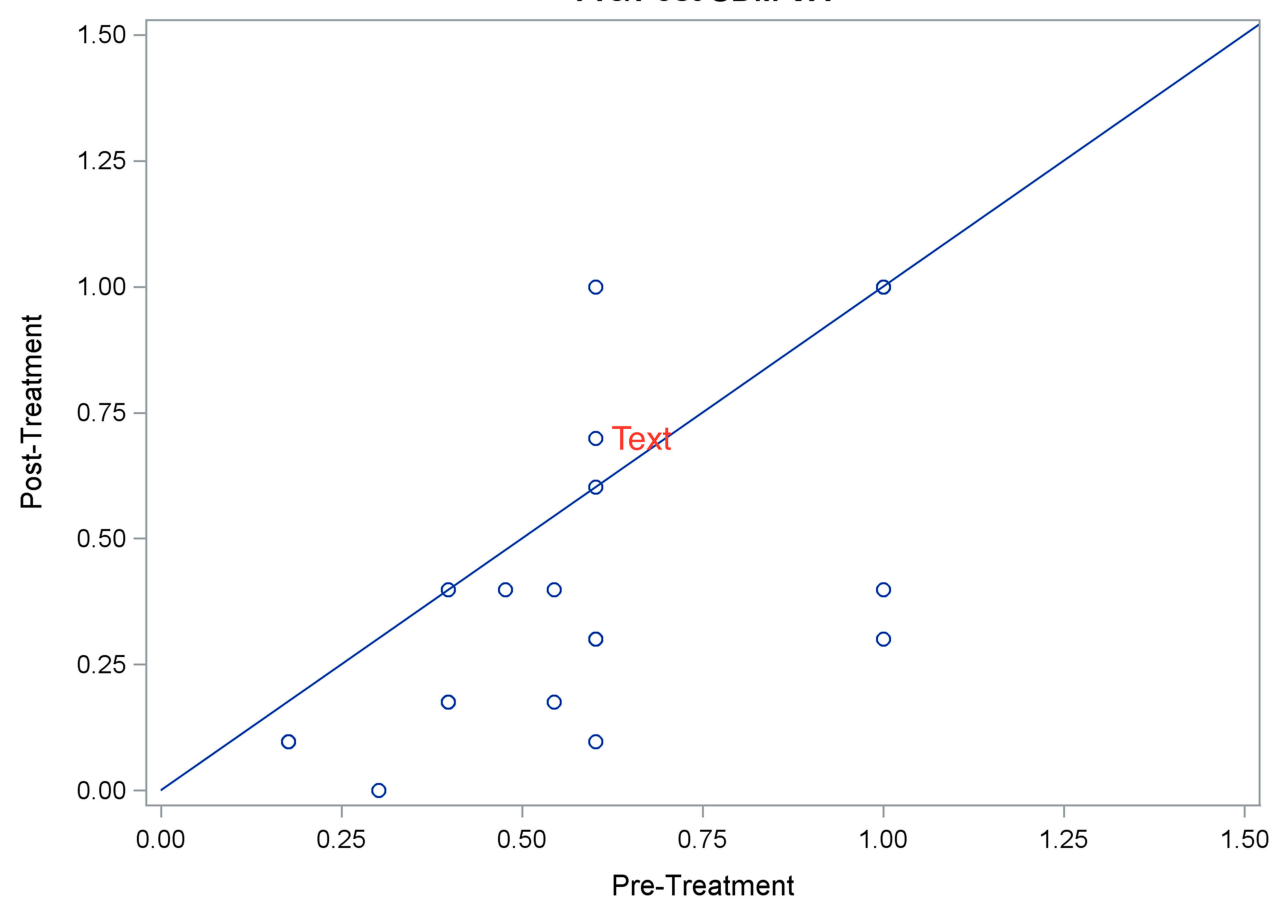

Figure I Scatter graph of logMAR visual acuities before and after SDM for persistent macular thickening after membrane peeling.

\section{Pre/Post SDM VA}

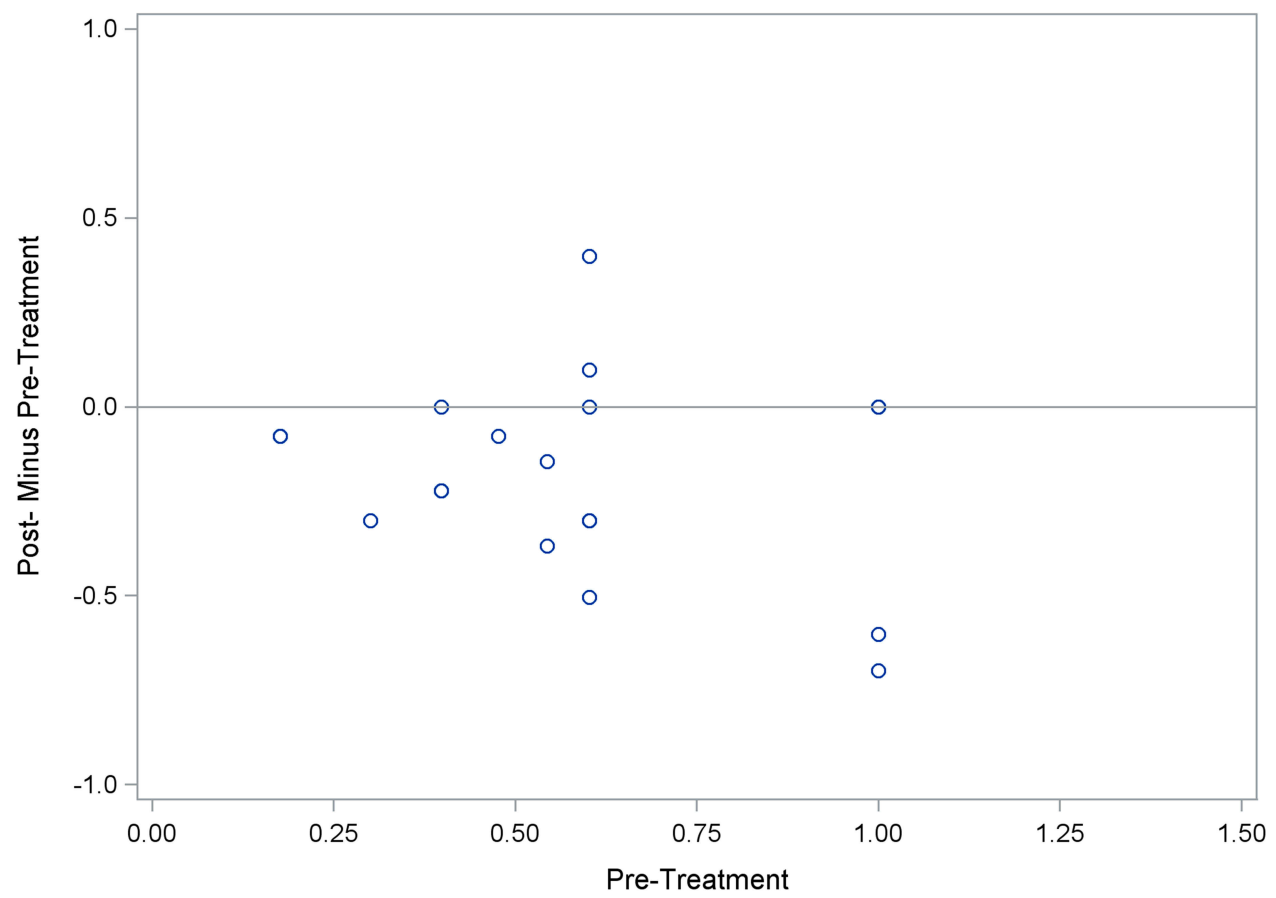

Figure 2 Scatter graph of post-treatment minus pre-treatment logMAR visual acuities after SDM for persistent macular thickening after membrane peeling. 


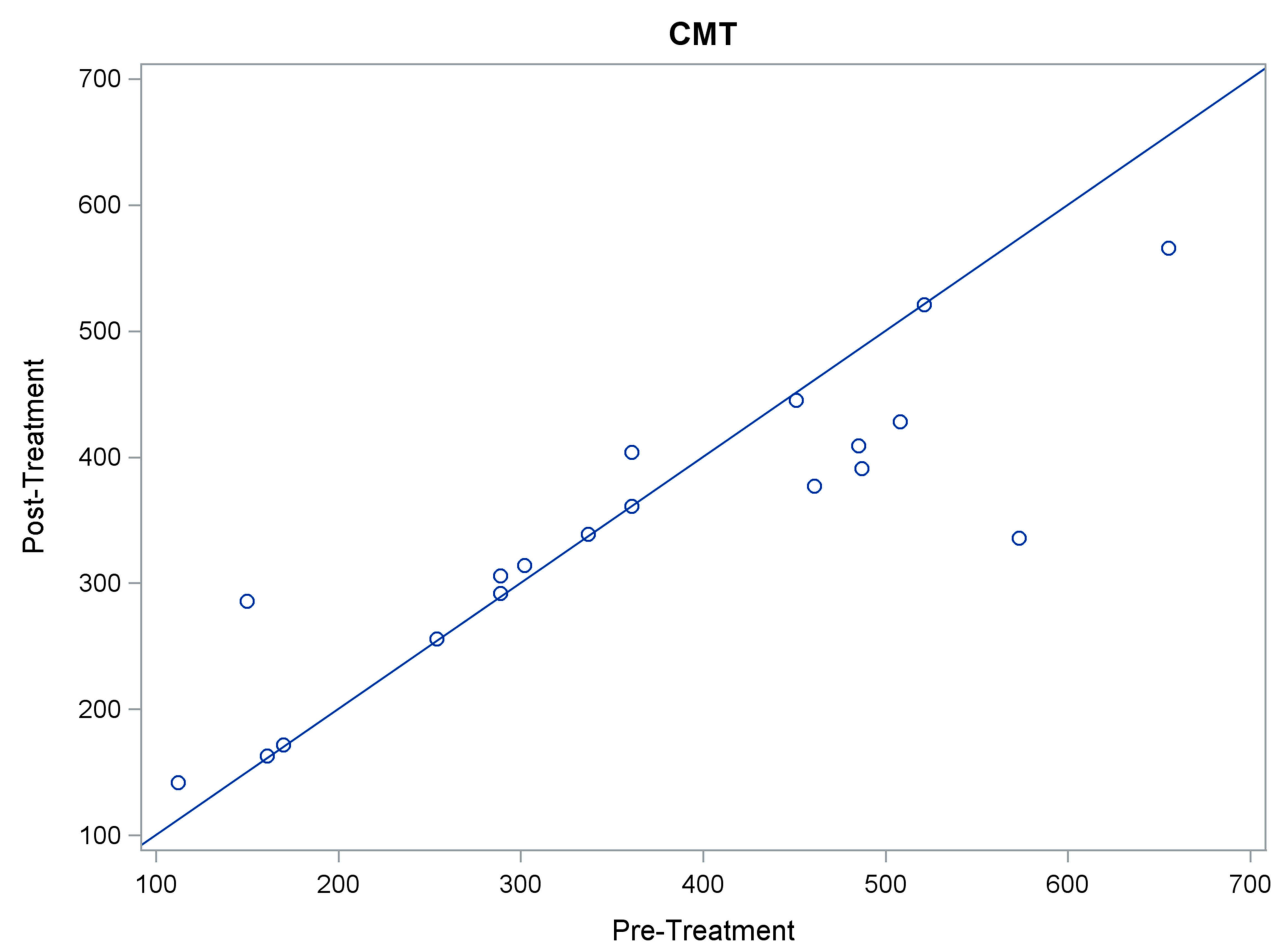

Figure 3 Scatter graph of central foveal thickness by OCT, in micrometers, before and after SDM for persistent macular thickening after membrane peeling.

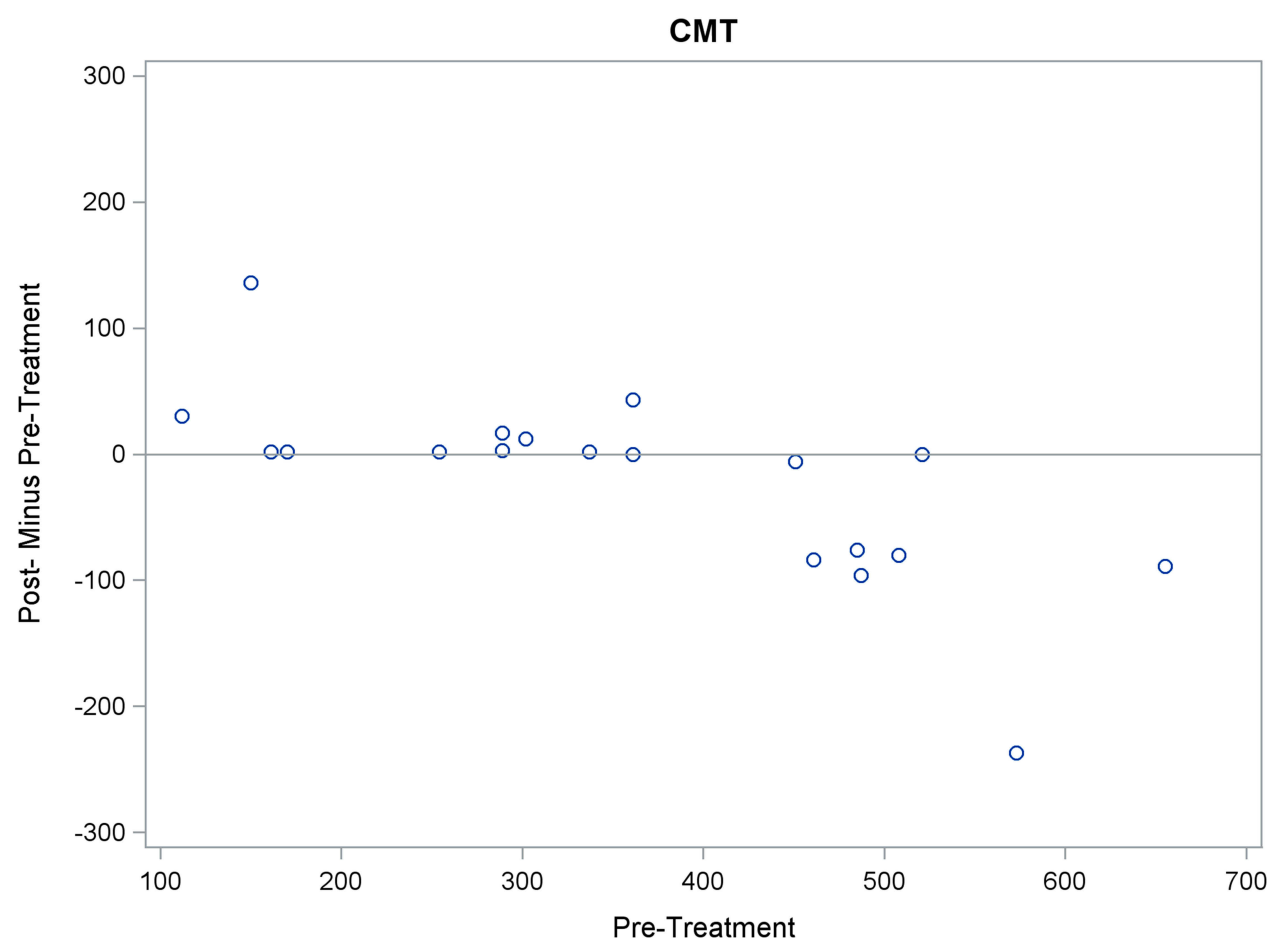

Figure 4 Scatter graph of post-treatment minus pre-treatment central foveal thickness by OCT, in micrometers, following SDM for persistent macular thickening after membrane peeling. 


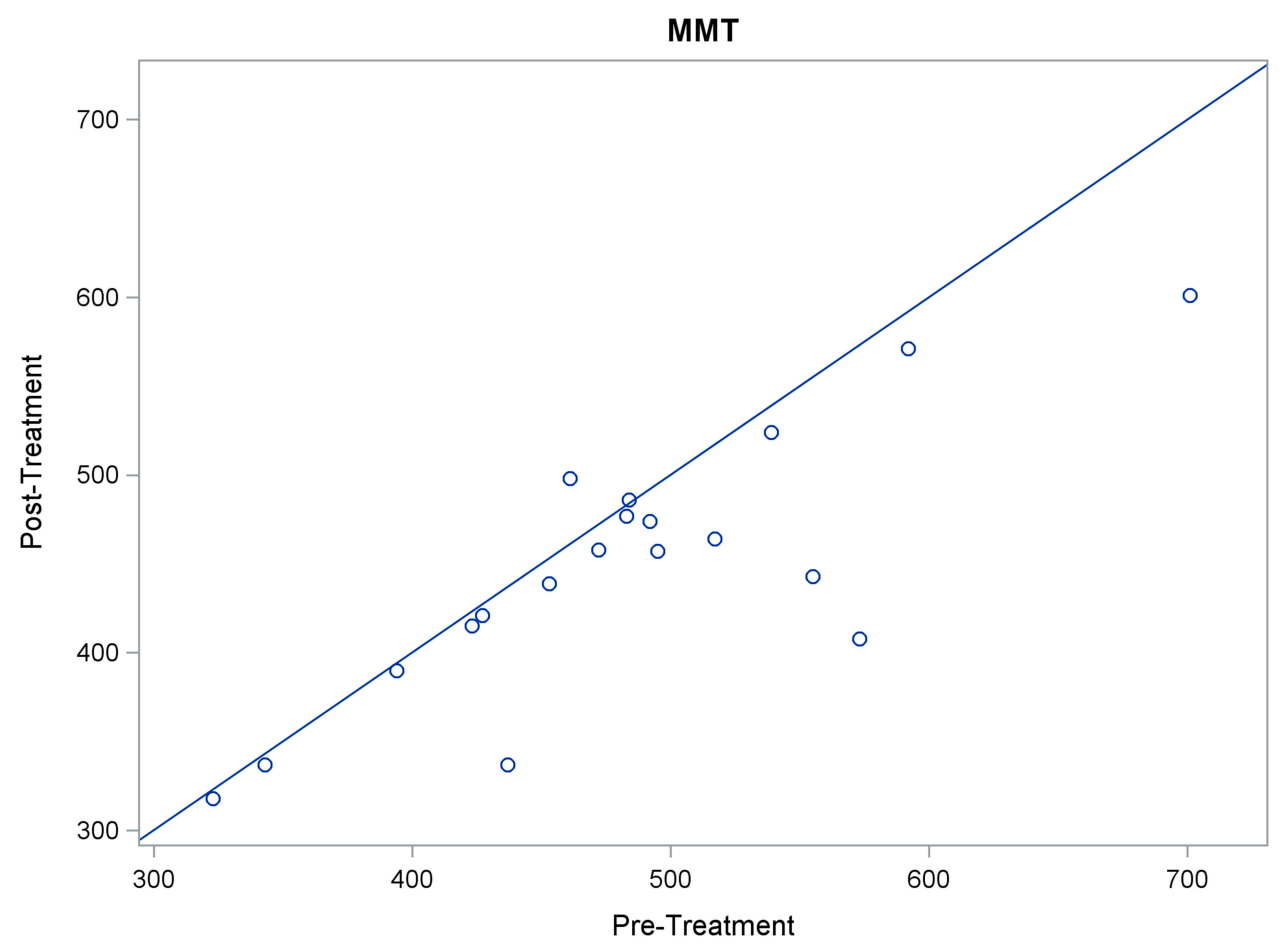

Figure 5 Scatter graph of maximum macular thickness by OCT, in micrometers, before and after SDM for persistent macular thickening after membrane peeling.

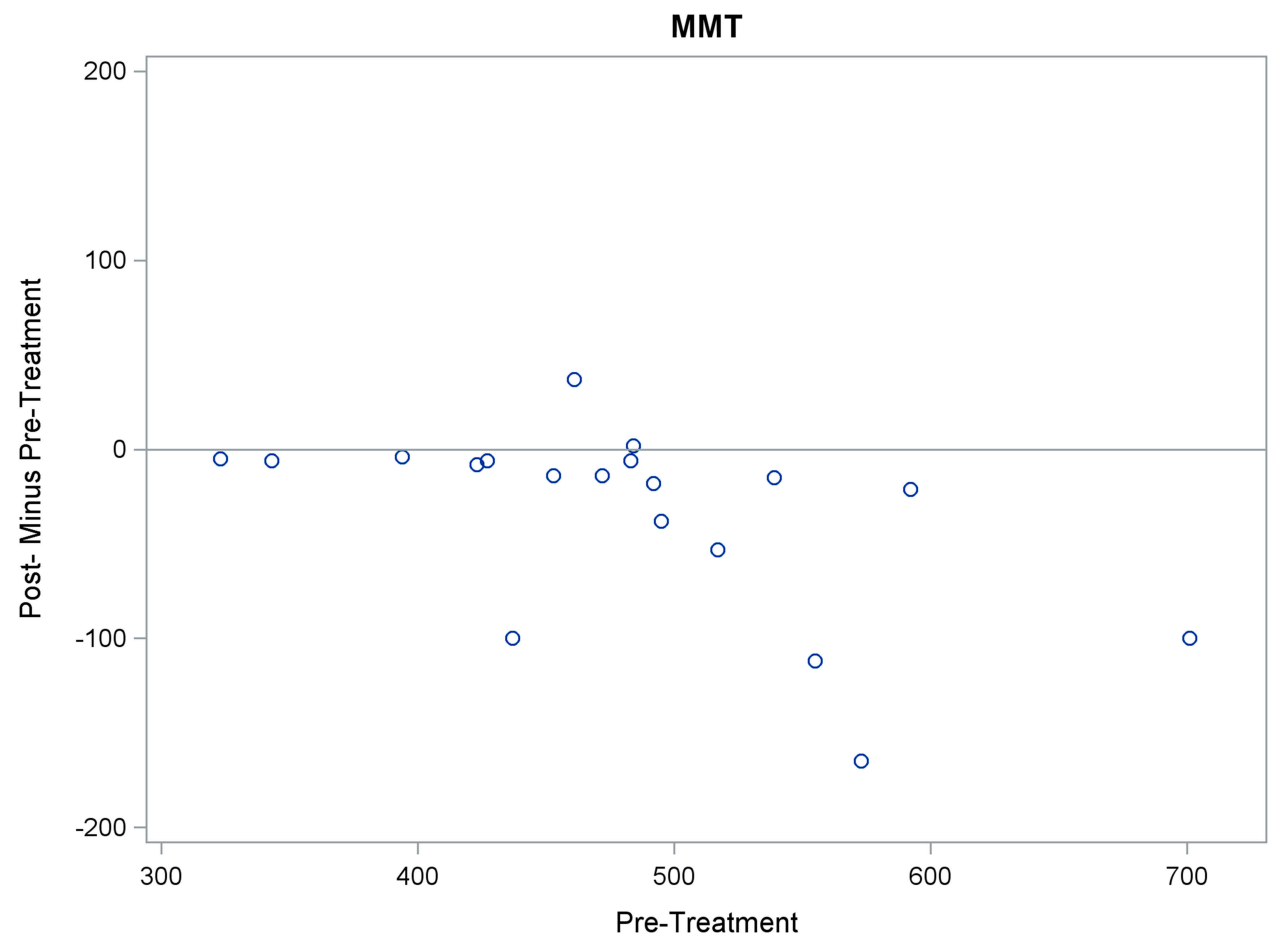

Figure 6 Scatter graph of post-treatment minus pre-treatment maximum macular thickness by OCT, in micrometers, following SDM for persistent macular thickening after membrane peeling. 
In this study, VA was significantly improved by membrane peeling $(\mathrm{p}=0.0004)$. However, despite such improvements, post membrane peeling VA may not improve as much as the patient, or surgeon, would like.

ERMs are often associated with macular thickening resulting from tangential epiretinal traction. ${ }^{1-3}$ This ERM-induced macular thickening may be either solid-appearing or cystic, and may demonstrate little to no leakage on intravenous fundus fluorescein angiography ${ }^{1}$ (Figures $7 \mathrm{C}$ and 9C). After membrane peeling, macular thickening generally improves, but may not resolve entirely and may limit visual recovery. Medical therapy is generally ineffective in this setting, possibly due to the frequent absence of angiographic leakage that might be amenable to treatment. ${ }^{3-5}$ Long-term persistence of abnormal macular thickening or edema may promote further degeneration of macular function over time. ${ }^{1-3}$ This is evident in the current study, where the maximum postmembrane peeling VAs deteriorated over time until SDM treatment.

It is notable, that following SDM, VAs improved without significant change in CFTs. The ability of SDM to significantly improve VA absent change in macular morphology is characteristic and well documented; first in the treatment of DME, but also following SDM treatment for
A

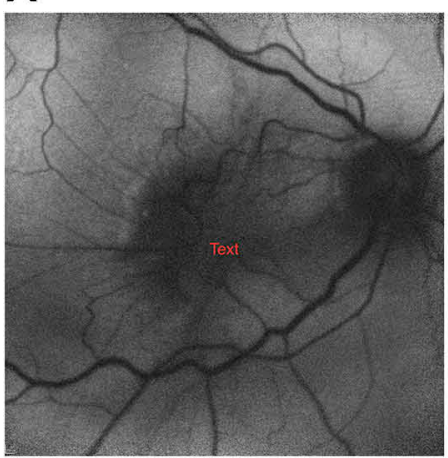

C

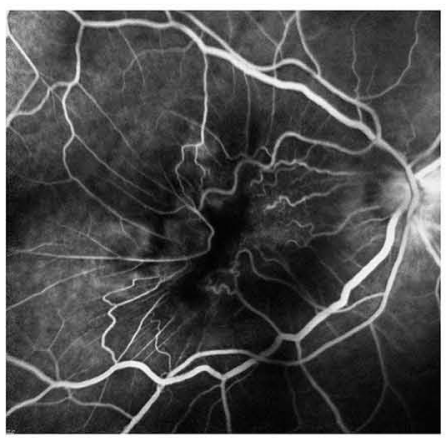

E
B

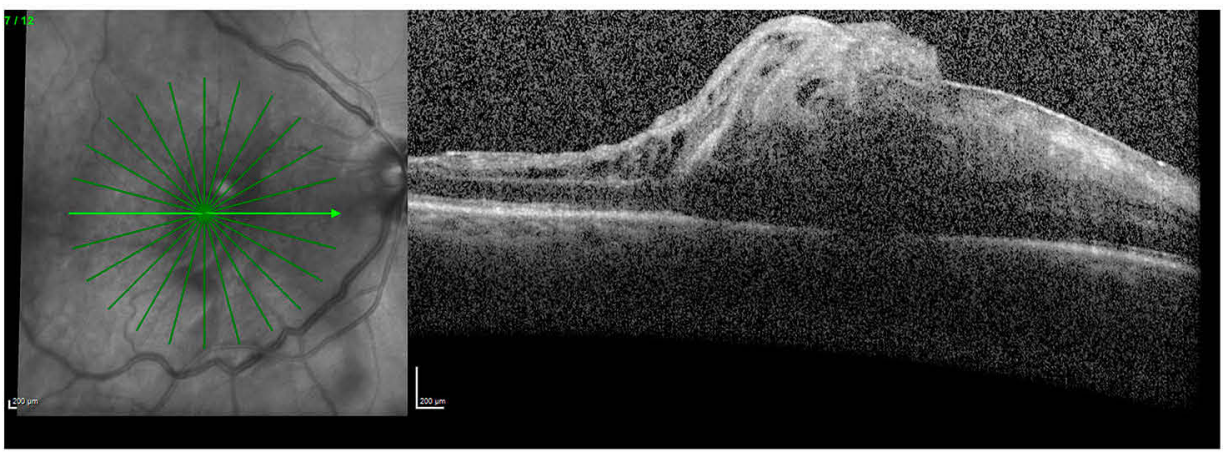

D

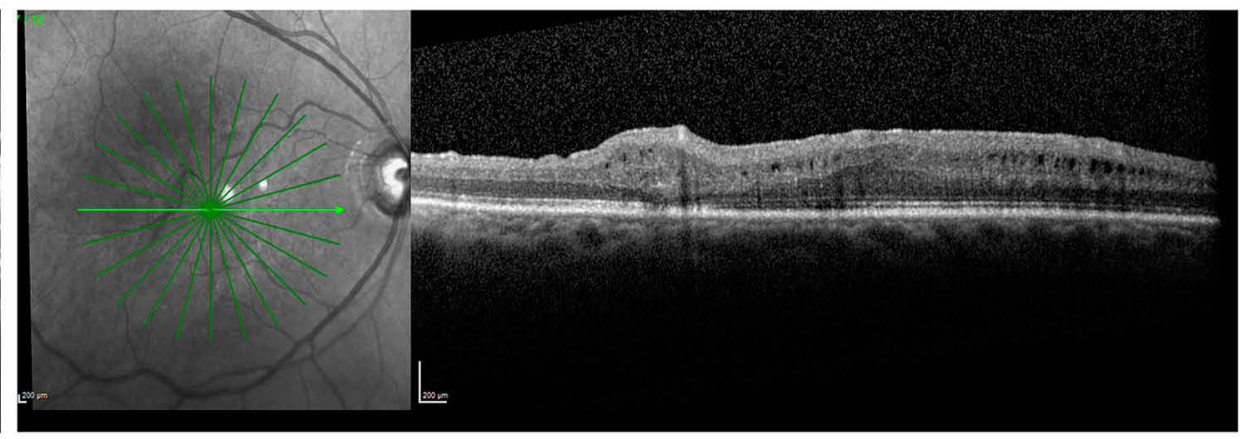

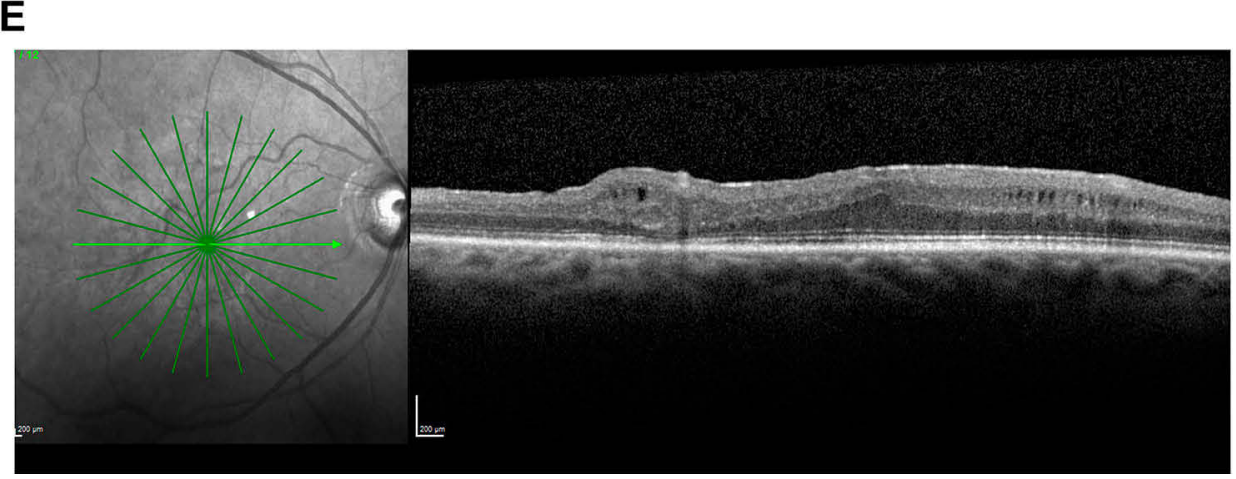

Figure 7 (A) Fundus photograph of the right eye with epiretinal membrane prior to membrane peeling. Visual acuity $=20 / 400$. (B) OCT of the same right eye with epiretinal membrane and marked macular thickening prior to membrane peeling. (C) Late-phase intravenous fundus fluorescein angiogram of the same eye prior to membrane peeling. Note the paucity of angiographic leakage within the macula. (D) OCT of the same eye 18 months following membrane peeling, at the time of SDM treatment. Visual acuity = 20/80. (E) OCT of the same eye 6 months after SDM. Visual acuity $=20 / 30$. 

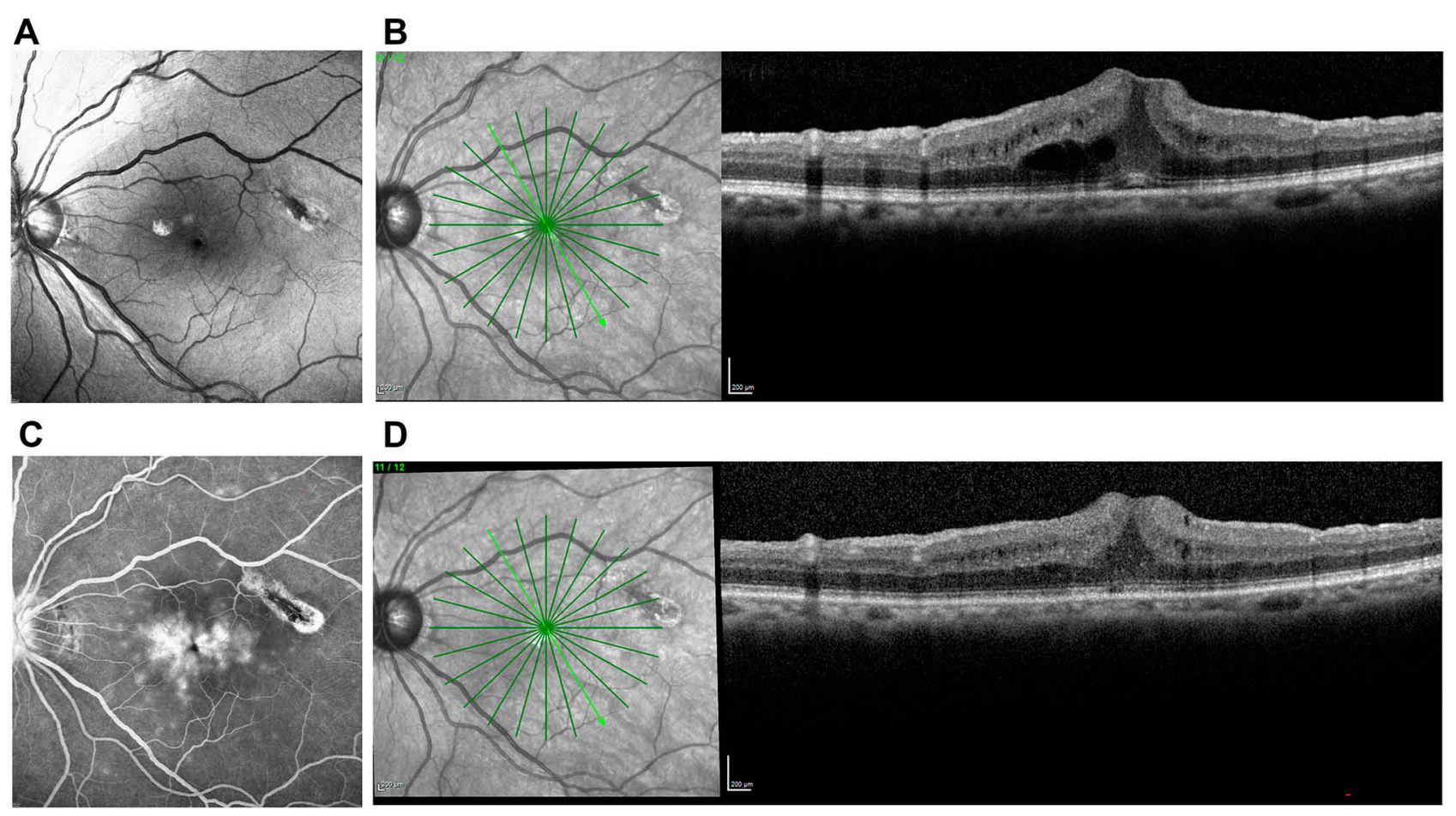

D

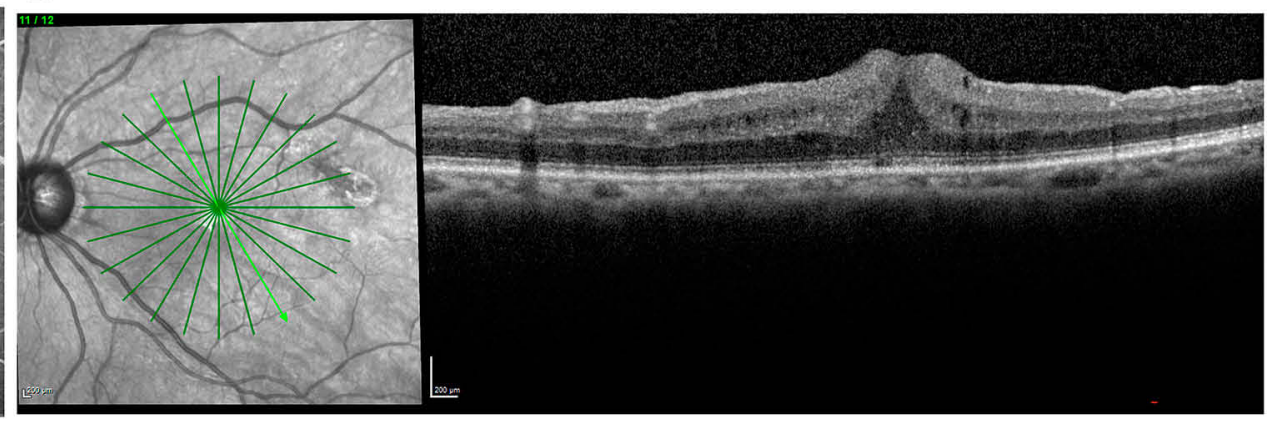

Figure 8 (A) Fundus photograph of left eye operated elsewhere for epiretinal membrane 2 years previously. Visual acuity $=20 / I 00$. (B) OCT of the same eye on the same date. Note marked macular thickening. (C) Intravenous fundus fluorescein angiogram of the same eye prior to SDM treatment demonstrating angiographic leakage within the macula. SDM was performed at this time. (D) OCT 4 months after SDM. Note the reduction in macular thickening. Visual acuity $=20 / 80$.

dry AMD, IRDs, and OAG. This uncoupling of function and morphology is indicative of the improvements in retinal physiology elicited by SDM. ${ }^{1-7,10-12,30-32}$

It is also interesting to note that while the CFT did not improve significantly following SDM, the MMT did. The reason(s) for this is unclear. Most likely, this reflects the fact that the avg. CFT prior to SDM treatment was less than the avg. MMT ( 365 vs $482 \mu \mathrm{m}$ ) leaving less room for CFT improvement; a relative ceiling effect. Another possibility is the fact that the CFT could only be taken at a single point - the foveal center, while the MMT might be anywhere - including coincident with the CFT - within the central $2 \mathrm{~mm}$ radius from the foveal center. This would increase the likelihood of capturing change (generally improvement) with the MMT measure.

The key effect of SDM is sublethal ("low-intensity") activation of RPE heat shock proteins. The HSP response, designed to preserve the cell in the face of existential threats, acts as a physiologic "reset", normalizing cell function. This cellular response is then amplified by "high-density" treatment of large areas of dysfunctional RPE designed to create an en-masse effect to maximize clinical effectiveness. By normalizing retinal function, SDM normalizes RPE cytokine/chemokine expression and response, and retinal autoregulation. SDM is anti-apoptotic and anti-oxidizing, increases tissue nitrous oxide, improves mitochondrial function; and is neuroprotective, improving Mueller cell, ganglion cell and optic nerve function. ${ }^{6-31} \mathrm{SDM}$ activates reparative acute inflammation absent tissue damage and decreases markers of chronic inflammation, stimulating reparative local and systemic immunomodulation and stem cell activation. ${ }^{27,28}$ Clinically, these SDM-elicited improvements in retinal physiologic and immune function have been documented by improved VA, contrast VA, microperimetry, mesopic visual function, pattern electroretinography, visually evoked potentials, and aqueous proteomics. ${ }^{10,12,21,31}$ As an enzymatic threshold phenomenon, SDM is a form of bioactivation and, via RPE HSP activation, a non-specific trigger of diseasespecific repair. ${ }^{15-20}$ This is because activated HSP-mediated intracellular protein repair is agnostic to the cause of protein misfolding and cellular dysfunction. ${ }^{15,16,19,22,25,26}$ The reset effect of SDM accounts for all observed clinical retinal laser effects for conventional retinal laser indications regardless of laser type and has successfully predicted novel new laser

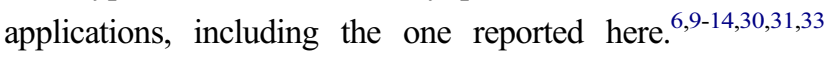
Having only therapeutic effects clinically, in vivo, or in vitro, 


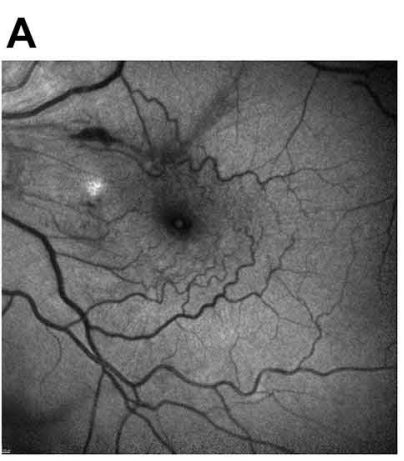

\section{B}
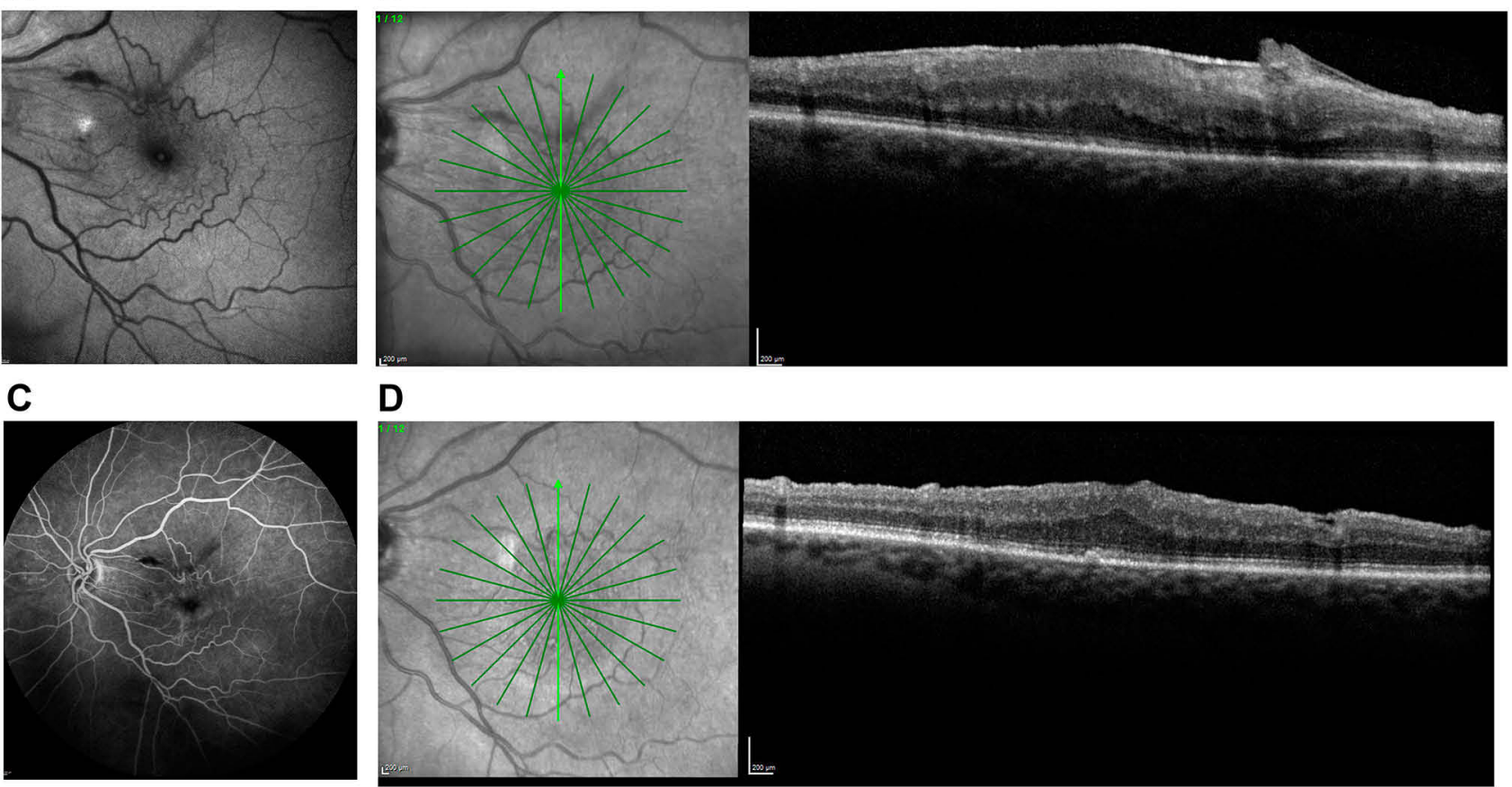

D

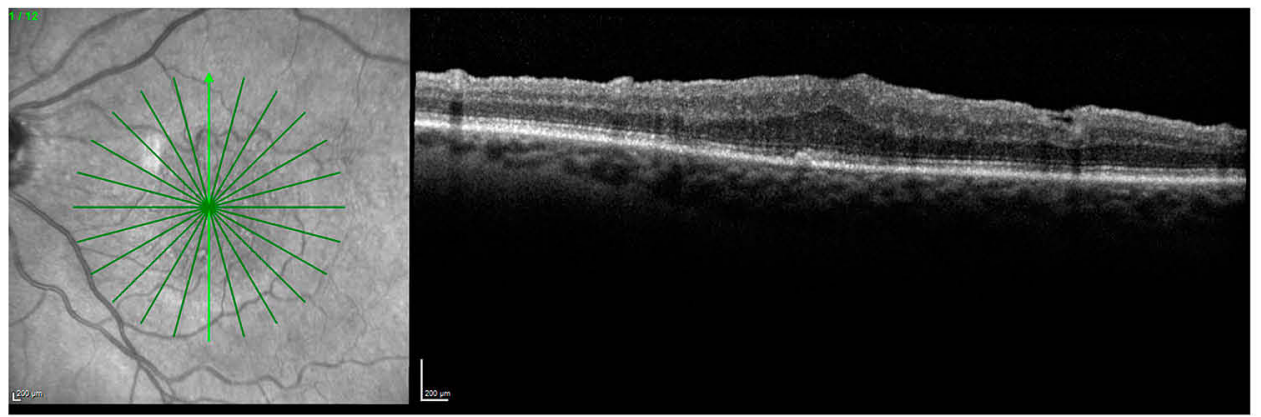

E

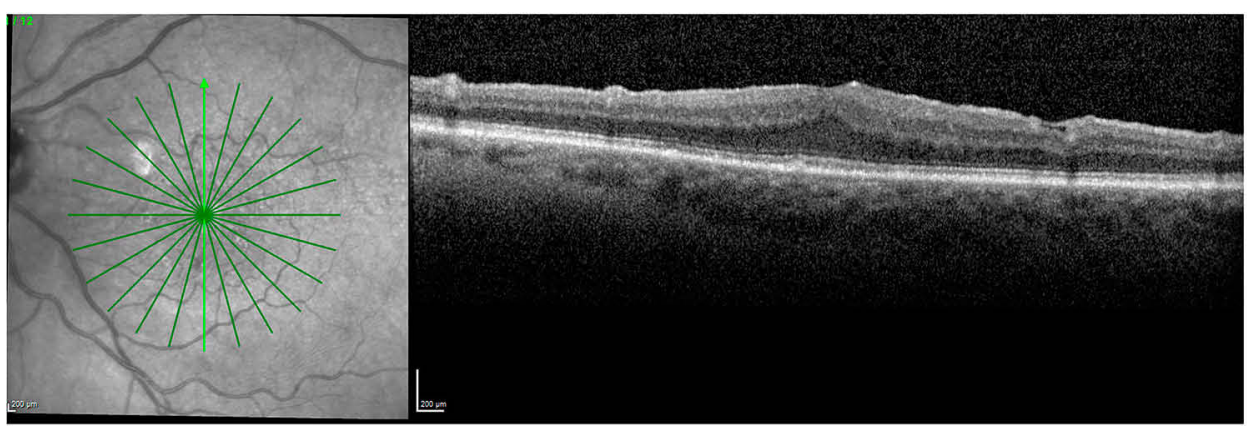

Figure 9 (A) Fundus photograph of the left eye with epiretinal membrane. Visual acuity $=20 / 400$. (B) OCT of the same eye on the same date. Note marked macular thickening. (C) Late-phase intravenous fundus fluorescein angiogram of the same date. Note the paucity of angiographic leakage in the macula. (D) OCT of the same eye 13 months after membrane peeling. Note persistent macular thickening. Visual acuity $=20 / 200$. SDM performed. (E) OCT II months after SDM. Note the reduction in macular thickening. Visual acuity $=20 / 30$.

the restorative effects of panmacular SDM are sufficient to account for improvements in the eyes reported here, such as the improvements in VA absent changes in CFT. ${ }^{15-20,22,25,26,30}$

Although the long-term follow-up post-SDM treatment is not the subject of the current report, it can be noted that, in some cases, the initial improvements in VA elicited by SDM required occasional retreatment to maintain. This highlights the utility of the unique safety of SDM, which allows retreatment whenever desired, and the mechanism of action, which makes treatment effects renewable without limiting factors common to drug therapy, such as tolerance or other adverse treatment effects. ${ }^{10,14,30}$

Might the improvements in macular thickness and VA reported here be simply coincidental, or reflect the natural history of progressive long-term post-membrane peeling visual improvements? Two observations suggest this is not the case; and that the reported improvements are indeed the result of panmacular SDM treatment. First, the average time of SDM treatment was almost 4 years after membrane peeling, long after any spontaneous post-membrane peeling improvements would be expected to occur. ${ }^{1-3}$ Second, these eyes, on average, did not show progressive VA improvement after membrane peeling. Instead, there was a period of initial improvement following membrane peeling, followed by a gradual secondary decline. This secondary VA decline appeared to be due to the degenerative influence of the persistent post-membrane peeling macular thickening. Instead of progressive improvement prior to SDM, the avg. VAs progressed from a maximum 


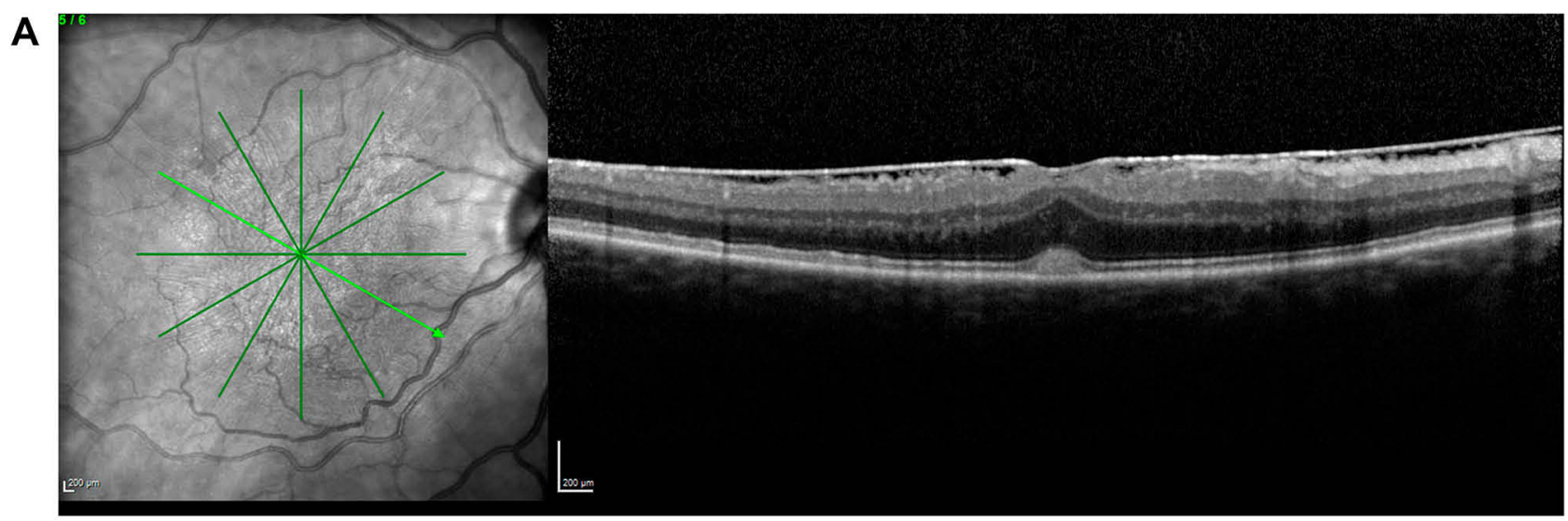

B

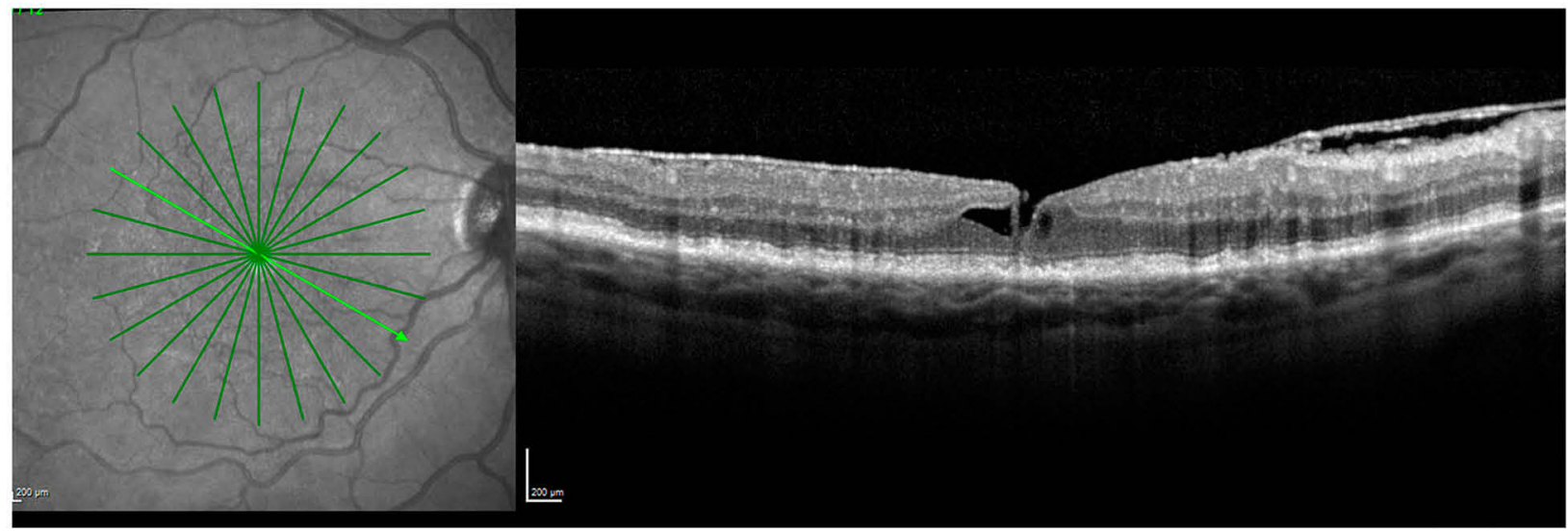

C

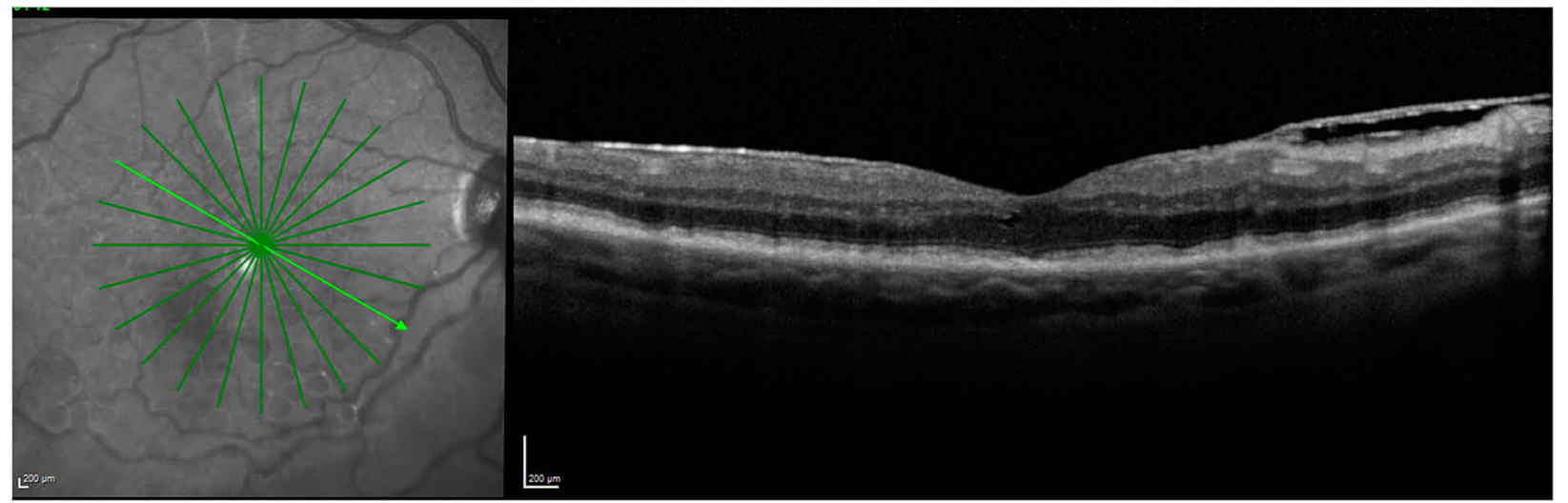

Figure 10 (A) OCT of a right eye with an epiretinal membrane. Visual acuity $=20 / 100$. (B) OCT of the same eye 7 years after membrane peeling with recurrent epiretinal membrane and lamellar foveal hole. VA $=20 / 70$. SDM performed. (C) OCT of the same eye 2 months after SDM. Note normalization foveal architecture after SDM alone. Visual acuity $=20 / 50$.

average VA of 20/72 after membrane peeling (and prior to SDM); to an average of 20/91 by the time of SDM treatment an average of 41 months later. Thus, it was not progressive postoperative visual improvement that improved further following SDM; it was progressive visual decline that was reversed by SDM, from an avg. VA of 20/91 at the time of SDM to an avg. VA of 20/68 after SDM.

This study suffers from the limitations inherent to small retrospective case reviews, including a small number of patients administered a novel treatment in a single-center, variable follow-up and intervention times, and the absence of controls. However, the treatment indication was identical in all eyes. Eyes with limited visual acuity and persistent macular thickening after membrane peeling improved following panmacular SDM, an avg. 41 months following vitrectomy. There were no adverse treatment effects, consistent with all prior studies of SDM for other treatment indications. There are no reliably effective treatments for limited visual recovery and persistent macular thickening following membrane peeling. This is an unmet need. The findings of the current study 
suggest that panmacular SDM may be helpful in this clinically common setting. ${ }^{1-3}$ Further prospective study is warranted.

\section{Informed Consent}

All patients included in this report provided informed consent prior to any and all procedures performed. As this report consists of patient unidentified data, no consent was required or obtained for data collection or reporting.

\section{Ethics and Consent Statement}

This study adhered to the tenets of the Declaration of Helsinki and was approved by the Western Investigational Review Board. The collection and evaluation of all protected patient health information were done in accordance with the Health Insurance Portability and Accountability Act (HIPPAA).

\section{Acknowledgment}

The author wishes to thank Taylor Blachley, MS, for his assistance in the statistical analysis of study data.

\section{Funding}

The author received no funding for research, authorship, and/or publication of this article.

\section{Disclosure}

The author reports management and equity from Ojai Retinal Technologies, LLC and Retinal Protection Sciences, LLC. He also reports equity from Replenish, Inc.

\section{References}

1. McDonald HR, Johnson RN, Ai E, Jumper JM, Fu AD. Macular Epiretinal Membranes. In: Ryan SJ, editor. Retina. 4th ed. St. Louis: Mosby; 2006:2509-2525.

2. Liu H, Zuo S, Ding C, Dai X, Zhu X. Comparison of the effectiveness of pars plana vitrectomy with and without internal limiting membrane peeling for idiopathic retinal membrane removal: a meta-analysis. J Ophthalmol. 2015;2015:974568. doi:10.1155/2015/974568.

3. Massin P, Allouch C, Haouchine B, et al. Optical coherence tomography of idiopathic macular epiretinal membranes before and after surgery. Am $J$ Ophthalmol. 2000;130(6):732-739. doi:10.1016/ S0002-9394(00)00574-2

4. Kauffmann Y, Ramel JC, Lefebvre A, et al. Preoperative prognostic factors and predictive score in patients operated on for combined cataract and idiopathic epiretinal membrane. Am J Ophthalmol. 2015;160(1):185-192. doi:10.1016/j.ajo.2015.03.027

5. Fine BS, Brucker AJ. Macular edema and cystoid macular edema. A J Ophthalmol. 1981;92:4330-4438.

6. Luttrull JK, Musch MC, Mainster MA. Subthreshold diode micropulse photocoagulation for the treatment of clinically significant diabetic macular edema. Br J Ophthalmol. 2005;89(1):74-80. doi:10.1136/bjo.2004.051540

7. Lavinsky D, Cardillo JA, Melo LA Jr., et al. Randomized clinical trial evaluating mETDRS versus normal or high-density micropulse photocoagulation for diabetic macular edema. Invest Ophthalmol Vis Sci. 2011;52(7):4314-4323. doi:10.1167/iovs.10-6828
8. Chen G, Tzekov R, Li W, et al. Subthreshold micropulse diode laser versus conventional laser photocoagulation for diabetic macular edema: A Meta-Analysis of Randomized Controlled Trials. Retina. 2016;36(11):2059-2065. doi:10.1097/IAE.0000000000001053

9. Luttrull JK, Spink CJ, Musch DA. Subthreshold diode micropulse panretinal photocoagulation for proliferative diabetic retinopathy. Eye. 2008;22(5):607-612. doi:10.1038/sj.eye.6702725

10. Luttrull JK, Margolis BWL. Functionally Guided Retinal Protective Therapy for Dry Age-Related Macular and Inherited Retinal Degenerations: A Pilot Study. Invest Ophthalmol Vis Sci. 2016;57 (1):265-275. doi:10.1167/iovs.15-18163

11. Luttrull JK. Improved retinal and visual function following subthreshold diode micropulse laser (SDM) for retinitis pigmentosa. Eye. 2018;32(6):1099-1110. doi:10.1038/s41433-018-0017-3.

12. Luttrull JK, Samples JR, Kent D, Lum BJ. Panmacular subthreshold diode micropulse laser (SDM) as neuroprotective therapy in primary open-angle glaucoma. In: John R, Samples, Paul A, editors. Glaucoma Research. Amsterdam, The Netherlands: Knepper (C) 2018 Kugler Publications; 2018-2020:281-294.

13. Luttrull JK, Sinclair SH, Elmann S, Glaser BM. Low incidence of choroidal neovascularization following subthreshold diode micropulse laser (SDM) for high-risk AMD. PLoS One. 13(8):e0202097. doi:10.1371/journal.pone.0202097.

14. Luttrull JK, Chang DB, Margolis BWL, Dorin G, Luttrull DK. Laser re-sensitization of medically unresponsive neovascular age-related macular degeneration: Efficacy and implications. Retina. 2015;35 (6):1184-1194. doi:10.1097/IAE.0000000000000458

15. Kregel K. Invited Review: Heat shock proteins: modifying factors in physiological stress responses and acquired thermotolerance. $J$ Appl Physiol. 2002;5(92):2177-2186. doi:10.1152/japplphysiol.01267.2001

16. Karu T. Photobiology of low-power laser effects. Rev Heal Phys. 1989;56(5):691-704. doi:10.1097/00004032-198905000-00015

17. Lavinsky D, Wang J, Huie P, et al. Nondamaging Retinal Laser Therapy: Rationale and Applications to the Macula. Invest Ophthalmol Vis Sci. 2016;57(6):2488-2500. doi:10.1167/iovs.15-18981

18. Luttrull JK, Sramek C, Palanker D, Spink CJ, Musch DC. Long-term safety, high-resolution imaging, and tissue temperature modeling of subvisible diode micropulse photocoagulation for retinovascular macular edema. Retina. 2012;32(2):375-386. doi:10.1097/ IAE.0b013e3182206f6c

19. Gao X, Xing D. Molecular mechanisms of cell proliferation induced by low power laser irradiation. J Biomed Sci. 2009;16(1):4. doi:10.1186/1423-0127-16-4

20. Inagaki K, Shuo T, Katakura K, Ebihara N, Murakami A, Ohkoshi K. Sublethal Photothermal Stimulation with a Micropulse Laser Induces Heat Shock Protein Expression in ARPE-19 Cells. J Ophthalmol. 2015;729792:2015.

21. Midena E, Bini S, Martini F, et al. Changes of aqueous humor Muller cells' biomarkers in human patients affected by diabetic macular edema after subthreshold micropulse laser treatment. Retina. 2018. doi:10.1097/IAE.0000000000002356.

22. Iwami H, Pruessner J, Shariaki K, Brinkmann R, Miura Y. Protective effect of a laser-induced sub-lethal temperature rise on RPE cells from oxidative stress. Exp Eye Res. 2014;124:37-47. doi:10.1016/j. exer.2014.04.014

23. Hattenbach LO, Beck KF, Pfeilschifter J, Koch F, Ohrloff C, Schake W. Pigment epithelium- derived factor is up regulated in photocoagulated human retinal pigment epithelial cells. Ophthalmic Res. 2005;37:341-346. doi:10.1159/000088263

24. Kolomeyer AM, Zarbin MA. Trophic factors in the pathogenesis and therapy for retinal degenerative diseases. Surv Ophthalmol. 2014;59 (2):134-165. doi:10.1016/j.survophthal.2013.09.004

25. Sramek C, Mackanos M, Spitler R, et al. Non-damaging retinal phototherapy: dynamic range of heat shock protein expression. Invest Ophthalmol Vis Sci. 2011;52(3):1780-1787. doi:10.1167/iovs.10-5917 
26. Karu T. Primary and secondary mechanisms of action of visible to near-IR radiation on cells. J Photochem Photobiol B. 1999;49 (1):1-17. (). doi:10.1016/S1011-1344(98)00219-X.

27. Caballero S, Kent DL, Sengupta N, et al. Bone Marrow-Derived Cell Recruitment to the Neurosensory Retina and Retinal Pigment Epithelial Cell Layer Following Subthreshold Retinal Phototherapy. Invest Ophthalmol Vis Sci. 2017;58(12):5164-5176. doi:10.1167/ iovs.16-20736

28. De Cilla S, Vezzola D, Farruggio S, et al. The subthreshold micropulse laser treatment of the retina restores the oxidant/antioxidant balance and counteracts programmed forms of cell death in the mice eyes. Acta Ophthalmol. 2018. doi:10.1111/aos.13995

29. Flaxel C, Bradle J, Acott T, et al. Retinal pigment epithelium produces matrix metalloproteinases after laser treatment. Retina. 2007;27(5):629-634. doi:10.1097/01.iae.0000249561.02567.fd
30. Luttrull JK, Sinclair SH. Safety of transfoveal subthreshold diode micropulse laser for fovea-involving diabetic macular edema in eyes with good visual acuity. Retina. 2014;34(10):2010-2020. doi:10.1097/IAE.0000000000000177

31. Luttrull JK, Kent D. Modern retinal laser for neuroprotection in openangle glaucoma. Samples JR, Ahmed IIK, editors. Current Developments in Glaucoma Surgery and MIGS. New Concepts in Glaucoma Surgery. 1. Amsterdam:Kugler Publications. September. 2019. In press.

32. Luttrull JK, Dorin G. Subthreshold diode micropulse laser photocoagulation (SDM) as invisible retinal phototherapy for diabetic macular edema: A review. Curr Diabetes Rev. 2012;8(4):274-284. doi:10.2174/157339912800840523

33. Chhablani J, Roh YJ, Jobling AI, et al. Restorative retinal laser therapy: Present state and future directions. Surv Ophthalmol. 2017; S0039-6257(17):2-30166. doi:10.1016/j.survophthal.2017.09.008.
Clinical Ophthalmology

\section{Publish your work in this journal}

Clinical Ophthalmology is an international, peer-reviewed journal covering all subspecialties within ophthalmology. Key topics include: Optometry; Visual science; Pharmacology and drug therapy in eye diseases; Basic Sciences; Primary and Secondary eye care; Patient Safety and Quality of Care Improvements. This journal is indexed on PubMed

\section{Dovepress}

Central and CAS, and is the official journal of The Society of Clinical Ophthalmology (SCO). The manuscript management system is completely online and includes a very quick and fair peer-review system, which is all easy to use. Visit http://www.dovepress.com/ testimonials.php to read real quotes from published authors. 